\title{
Using light to improve commercial value
}

\author{
Matthew Alan Jones ${ }^{1}$
}

\begin{abstract}
The plasticity of plant morphology has evolved to maximize reproductive fitness in response to prevailing environmental conditions. Leaf architecture elaborates to maximize light harvesting, while the transition to flowering can either be accelerated or delayed to improve an individual's fitness. One of the most important environmental signals is light, with plants using light for both photosynthesis and as an environmental signal. Plants perceive different wavelengths of light using distinct photoreceptors. Recent advances in LED technology now enable light quality to be manipulated at a commercial scale, and as such opportunities now exist to take advantage of plants' developmental plasticity to enhance crop yield and quality through precise manipulation of a crops' lighting regime. This review will discuss how plants perceive and respond to light, and consider how these specific signaling pathways can be manipulated to improve crop yield and quality.
\end{abstract}

\section{Introduction}

The effective application of light is essential for plant husbandry, but the demands of modern, intensive horticulture often conflict with the optimal planting strategy for plant growth. Dense planting regimes induce shading throughout the canopy, with individual plants striving to optimize light harvesting at the expense of their neighbors. This intra-crop competition leads to a varied light environment that has consequences for crop uniformity and total yield, which is exacerbated by changing light availability over the course of the year ${ }^{1}$. Historically, horticulturalists have sought to mitigate these effects through the development of varieties with altered developmental responses that improve harvest. Alternatively, enclosed glasshouses enable control of light, temperature, humidity, and $\mathrm{CO}_{2}$, each of which can alter plant development. The recent advent of commercially-viable LEDbased lighting provides an additional opportunity to optimize plant development through the application of specific light wavelengths at times most appropriate to optimize crop traits. These manipulations will be of immediate benefit for glasshouse-grown plants where supplemental light can be readily provided, although as LED technology advances there will be opportunities to

\footnotetext{
Correspondence: Matthew Alan Jones (matthew.jones@essex.ac.uk)

${ }^{1}$ School of Biological Sciences, University of Essex, Wivenhoe Park, Essex, Colchester CO4 3SQ, UK
}

apply similar approaches in the field. This review will summarize our understanding of plant perception and photomorphology and how this can be applied to optimize plant growth.

\section{Plant photoreceptors}

As photosynthetic organisms, plants need to harvest sufficient light energy to sustain growth and reproduce. However, it is not sufficient to simply irradiate plants with a single quality of light. Although monochromatic red or blue light sources (as chlorophyll predominantly absorbs light in the red and blue portions of the spectrum) can be used to cultivate crops, such plants develop atypically. This is likely because of the imbalanced activation of different photoreceptors which ultimately impairs photosynthesis either through inappropriate stomatal behavior or incorrect accumulation of photosynthetic pigments $^{2,3}$. Plants sense light both through specific photoreceptors as well as by monitoring the metabolic consequences of photosynthesis ${ }^{4,5}$, thereby allowing light to be used as a predictive environmental indicator as well as an energy source. Shortening days imply the onset of winter and subsequent reductions in temperature whilst the spectrum of light provided by the sun is enriched in the blue portion of the spectrum at dawn and dusk relative to midday ${ }^{6}$. Given these environmental characteristics, plants have evolved sophisticated mechanisms to 


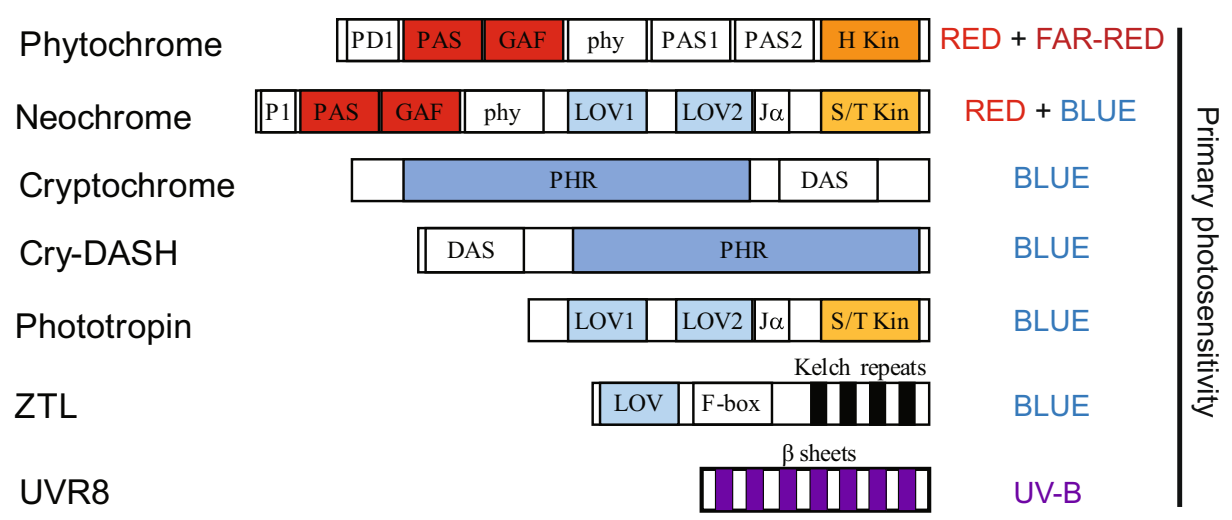

Fig. 1 Schematic diagram illustrating major domain structure of plant photoreceptors. Domains necessary for red light detection are shown in red, whilst those for blue light detection are shown in blue. The N-terminal phytochrome PAS and GAF domains interlink to allow binding of a phytochromobilin chromophore whilst the cryptochrome PHR domain associates with FAD and MTHF chromophores. LOV domains bind a FMN chromophore. Kinase domains are highlighted in orange. DAS Drosophila, Arabidopsis, Synechocystis cryptochrome domain, FAD Flavin Adenosine Dinulceotide, FMN Flavin Mono-Nucleotide, GAF CGMP specific and -regulated cyclic nucleotide phosphodiesterase, Adenylyl cyclase, and FhIA, $H$ Kin Histidine kinase, Ja Ja-helix, LOV Light/Oxygen/Voltage sensitive, MTHF Methenyltetrahydrofolate, PAS Per/Arnt/Sim, PD1 Phytochrome Domain 1, PHR Photolyase Homology Region, phy-Phytochrome domain 4, S/T Kin Serine/Threonine kinase

determine light availability and quality. Decades of research have revealed a complex network of photosensory pathways that enable plants to precisely respond to light quantity, quality, and duration ${ }^{5,6}$. Perhaps more importantly, plants are able to respond and adapt to each of these stimuli. In an evolutionary context, plants responses to light have been selected to maximise their survival; the challenge facing horticulturalists is how these existing light-responsive traits can be modified or selectively activated to increase yield and crop quality.

In contrast to animals, which have evolved specialized light sensing organs, plants perceive light in a cellautonomous fashion. Plants have evolved a suite of photoreceptors (Fig. 1), each of which provide sensitivity to different portions of the light spectrum by binding a light absorbing co-factor (referred to as a chromophore). Red and far-red light $(600-750 \mathrm{~nm})$ is primarily detected by the phytochrome family ${ }^{8}$ while blue and UV-A light $(320-500 \mathrm{~nm})$ is sensed by cryptochromes, phototropins, and members of ZEITLUPE/ADAGIO family ${ }^{7,9-11}$. UV-B light $(290-320 \mathrm{~nm})$ is perceived by the UVR8 photoreceptor ${ }^{12}$. In addition to these characterised photosensors, plants are also able to respond to 'green' light $(500-600 \mathrm{~nm})$, although the photoreceptors responsible for these responses have not been elucidated ${ }^{13}$. The existence of distinct photoreceptor families provides opportunities to selectively activate individual pathways, thereby precisely controlling plant development.

\section{Phytochromes}

Phytochromes were initially identified in 1959 as the photoreceptor that mediates plant photomorphogenesis in response to long-wavelength visible light ${ }^{14}$. The phytochrome family has since been found to be ubiquitous amongst seed plants and cryptophytes, with examples also being found in cyanobacteria, nonphotosynthetic bacteria, and fungi ${ }^{15}$. Phytochromes (phy) are sensitive to irradiation by both red and far-red light, and uniquely function by measuring the relative quantity of each of these wavelengths ${ }^{15}$. The phytochrome basal state (designated $\mathrm{P}_{\mathrm{r}}$ ) is sensitive to red light and upon irradiation is converted to a far-red sensitive state $\left(P_{\text {fr }}\right)$. Reversion to the $P_{r}$ form occurs either after far-red light exposure or as a consequence of dark incubation. The relative amounts of each of these forms determine downstream signalling events, with the $\mathrm{P}_{\mathrm{fr}}$ form considered to be the active signalling state ${ }^{16}$.

Higher plant genomes encode a suite of phytochrome proteins, each with slightly diverged light-sensitivity and function. Angiosperm phytochromes can be placed into two broad groups based upon the stability of the red light irradiated $\mathrm{P}_{\mathrm{fr}}$ form. Type I phytochromes (such as phyA) accumulate in the dark and are rapidly degraded after illumination ${ }^{17}$. Type I phytochromes are primarily involved in very low light responses (VLFR) or those involving a high irradiance response (HIR), two signalling modes that are functionally different and appear to operate through at least partially distinct pathways ${ }^{18}$. Type II phytochromes (such as phyB-E) remain stable in the presence of light allowing these phytochromes to respond persistently to fluctuations in illumination (low fluence response, $\mathrm{LFR}^{19,20}$. LFR responses (such as shade avoidance) are reversible and are determined by the ratio of red and far red light used to irradiate the plant ${ }^{21}$. VLFR, HIR, and LFR interact to facilitate light sensitivity under a broad range of light conditions. As phyA is light-labile, 
phyA is generally considered to be the primary photoreceptor in etiolated seedlings, with phyB and other type II phytochromes having greater importance in lightgrown plants with regards shade avoidance and the regulation of flowering time (Fig. $2^{21}$ ).

\section{Cryptochromes}

Plant cryptochromes are blue light photoreceptors that are one of five subfamilies identified in the photolyase/ cryptochrome family based on molecular phylogenetic analyses and functional similarity ${ }^{22}$. Cryptochromes have been identified in the model plant Arabidopsis thaliana, the closely related Brassica napus, and in a number of other model plant systems including pea, rice, and tomato $^{10}$. The majority of plant genomes studied encode for two canonical plant cryptochrome proteins (CRY1 and CRY2) and one member of the CRY-DASH subfamily, which has been designated CRY3 (Fig. $1^{23-26}$ ).

Cryptochromes perceive blue light via a flavin adenine dinucleotide chromophore, with blue light irradiation triggering conformational changes that culminate in cryptochrome dimerization and the activation of biochemical signalling pathways ${ }^{9,27}$. While CRY1 is stable when illuminated, CRY2 is degraded after light activation $^{25,28,29}$. Cryptochromes largely induce changes in plant development through changes in gene expres$\operatorname{sion}^{30,31}$. These changes in gene expression induce physiological changes from de-etiolation through to flowering, and also have a role in the production of anthocyanins (Fig. $2^{32}$ ). Cryptochromes have been found associated with DNA, but also activate CRYPTOCHROME INTERACTING BASIC HELIX LOOP HELIX (CIB) transcription factors and the CONSTITUTIVELY PHOTOMORPHOGENIC1 (COP1) and PHYTOCHROME INTERACTING FACTOR (PIF) signalling hubs (Fig. $2^{33,34}$ ).

\section{Phototropins}

Phototropins are plasma membrane-localised protein kinases which were initially characterised in Pisum

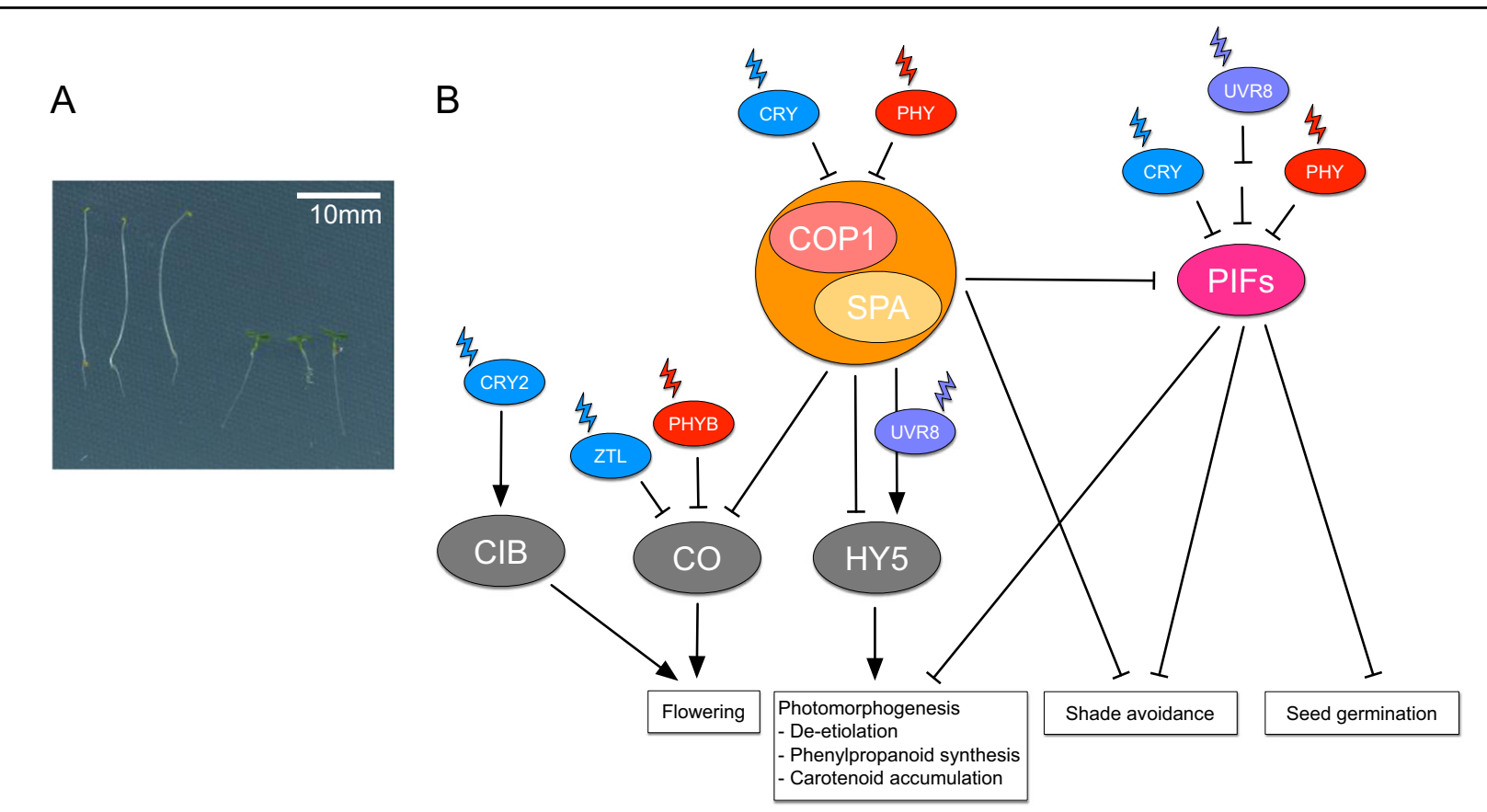

Fig. 2 Photomorphogenesis is regulated by conserved signalling hubs. a In the absence of light, seedlings have an etiolated phenotype (left). Upon perceiving light, plants initiate photomorphogensis leading to dramatic changes in plant architecture including cotyledon expansion and the inhibition of hypocotyl elongation (right). b Cryptochromes, phytochromes, and UVR8 perceive blue, red, and UV-B light respectively (see the section 'Plant photoreceptors'). Phytochromes and cryptochromes inhibit the activity of both the COP1/SPA and PIF signalling hubs, leading to changes in gene expression that culminate in photomorphogenesis and shade avoidance responses. Activated UVR8 modulates the function of the COP1/SPA complex to promote photomorphogenesis. The COP1/SPA complex has additional roles in the regulation of flowering, while PIFs influence seed germination. Cryptochromes and phytochromes also influence plant development independently of these signalling hubs; for instance CRY2 (see the section 'Cryptochromes') accelerates flowering via CIB transcription factors whereas phyB (see the section 'Phytochromes') inhibits CO accumulation in the morning independently of COP1 (see the section 'Shade avoidance'). CIB CRYPTOCHROME INTERACTING BASIC HELIX LOOP HELIX, CO CONSTANS, COP1 CONSTITUTIVELY PHOTOMORPHOGENIC1, CRY Cryptochrome, HY5 ELONGATED HYPOCOTYL5, PHY Phytochrome, PIF PHYTOCHROME INTERACTING FACTOR, UVR8 UV-B RESISTANCE LOCUS8, ZTL ZEITLUPE 
sativum membrane extracts due to their blue-lightdependent phosphorylation ${ }^{35}$, Fig. 1). As in other photoreceptors, blue light induces conformational changes that generate a biologically-active state which gradually reverts to the dark-adapted form in the absence of light ${ }^{9}$. Since the identification of the PHOT1 locus in Arabidopsis ${ }^{36}$, phototropins have been characterised in numerous other dicots and monocots, as well as in lower plants such as the fern Adiantum capillis-veneris ${ }^{37}$. Studies have identified two primary members of the phototropin family, phototropin (phot) 1 and $2^{36,38,39}$, both of which are found in Arabidopsis. The phots have partially redundant roles in many responses in Arabidopsis, but have some diverged functions; in general phot 1 is sensitive to lower fluences of light while phot2 acts in response to higher light intensities $^{40}$. Like phytochromes and cryptochromes, phots are capable of eliciting changes in gene expression in response to blue light stimulation, although compared to the modulation of gene expression induced by cryptochrome activity this role is minor ${ }^{41}$. Instead, phots are thought to act primarily at a post-transcriptional level to mediate responses to blue light. Phototropins have been shown to be the primary light receptors for a range of blue light-specific responses including phototropism (after which they were named), chloroplast accumulation, leaf positioning and expansion and also stomatal opening ${ }^{42}$. In addition, phot 2 induces chloroplast avoidance movements under high light irradiation ${ }^{42}$.

Phot1 and phot2 appear to have evolved from a single gene duplication event after the evolution of seed plants $^{36,39,43}$. Single copies of PHOT are found in pteridophytes and in the single-celled algae Chlamydomonas reinhardtii ${ }^{44,45}$ and are likely derived from the ancestral PHOT gene ${ }^{43}$. In addition to these sequences, a chimeric photoreceptor (neochrome 1, neo1) has been identified in Adiantum and the alga Mougeotia scalaris which contains the red light-sensing $\mathrm{N}$-terminal region of a phytochrome fused with a complete phototropin protein ${ }^{46}$. This fusion event allows both red and blue light to be used to induce what are primarily thought to be blue light-mediated phot-dependent responses in higher plants. This is thought to be advantageous in the shaded, low light environments in which these plants are commonly found ${ }^{47}$. Indeed, neochrome is thought to have arisen on two independent occasions in cryptophytes ${ }^{46}$.

\section{ZEITLUPE family}

The ZEITLUPE (ZTL) family consists of three members; ZEITLUPE (ZTL), FLAVIN BINDING, KELCH REPEAT, F-BOX1 (FKF1) and LOV KELCH PROTEIN2 $(\mathrm{LKP} 2)^{48-50}$. Each of these proteins have a conserved structure consisting of an $\mathrm{N}$-terminal LOV domain, an Fbox domain which allows binding to a SKP1-CUL1-FBP
(SCF) ubiquitin ligase, and a region of kelch repeats which are also thought to allow protein-protein interactions ${ }^{51}$. The existence of a light sensitive LOV domain coupled with an F-box suggested that these proteins may be involved in the light-dependent regulation of protein stability. Indeed, recent work has shown a role for ZTL and FKF1 in the circadian system where their lightdependent function allows modulation of internal timing signals $^{52-54}$. This mechanism allows plants to induce flowering at favorable times of year by responding to seasonal changes in day length through light-dependent modulation of circadian clock signals ${ }^{52,55}$ (see the section 'Photoreceptors contribute to temperature sensitivity and endogenous timing signals').

\section{UVR8}

Although not detected by the human eye, sunlight contains a small proportion $(<0.5 \%)$ of UV-A $(315-400$ $\mathrm{nm})$ and UV-B (280-315 nm) light ${ }^{56}$. Plants perceive light via the UV-B RESISTANCE8 (UVR8) photoreceptor ${ }^{57,58}$, with loss of this photoreceptor leading to enhanced susceptibility to UV-B radiation ${ }^{59}$. UVR8 disassociates from its homodimer in the presence of UV-B light, with the resultant monomers binding with partners such as COP1 to induce changes in gene expression ${ }^{60-63}$. Although damaging in large quantities, UV-B induced signalling via the UVR8 pathway also has important benefits, promoting pest resistance, increasing flavonoid accumulation in fruits, improving photosynthetic efficiency, and serving as an indicator of direct sunlight and sunflecks ${ }^{56,64-68}$.

\section{Photoreceptors contribute to temperature sensitivity and endogenous timing signals Activated photoreceptors contribute to temperature perception}

Although light serves a vital role in plant development it is important to consider how photoperception is integrated with other environmental information such as ambient temperature and time of day. Although a thorough discussion of plants responses to temperature are outside the scope of this review (see ${ }^{69,70}$ for recent overviews) it is becoming apparent that photoreceptors directly contribute to temperature perception. Recent work reveals that the stability of the light-activated states of phytochromes and phototropins is prolonged at lower temperatures through retardation of dark reversion ${ }^{71-73}$. This modulation of light signalling pathways by temperature allows immediate integration of these important environmental signals. This is particularly important in the context of LED lighting systems where the utilization of monochromatic light sources may have unintended consequences for plants perception of temperature through the specific activation of individual families of photoreceptors. 


\section{Plants responses to light are informed by the circadian system}

While we have characterized many of the photoreceptors utilized by plants (see the section 'Plant photoreceptors') it is also apparent that biological timing mechanisms have arisen that regulate plants' responses to these signals ${ }^{4,74}$. The circadian system is an internal timekeeping mechanism that consists of interlocking transcription/translation loops that generate an approximate 24-h cycle $^{75}$. Approximately one third of the expressed transcriptome is regulated by the circadian system, with transcription of phytochromes, cryptochromes, phototropins, and UVR8 each being regulated by the circadian system ${ }^{76-78}$. In addition, the clock modulates photosensory pathways such that plants perception of light also varies during the day, a concept known as circadian gating ${ }^{74,79}$. The biological clock allows plants to anticipate daily environmental changes as well as acting as a reference to measure seasonal changes in day length ${ }^{75,80}$, consequently contributing to flowering time in photoperiod-sensitive species (see the section 'Photoperiodic control of flowering time').

Conversely, the circadian system is highly responsive to light, a quality necessary to ensure accurate perception of changing day lengths during the year. The loss of cryptochromes, or the removal of individual or multiple phytochromes, alters the progression of the circadian cycle under constant blue or red light respectively ${ }^{81-83}$. The ZTL family of blue light photoreceptors, named after the predominant member ZEITLUPE (ZTL), have similarly been shown to have a role in regulating the circadian system, with the other two ZTL family members, LKP2 and FKF1, providing partial redundancy for ZTL function $^{84,85}$. The temporal regulation initiated by the clock, and its sensitivity to light, provide additional opportunities to precisely control crop development in response to light and should be considered when designing optimal lighting regimes for crops.

\section{Plant development is controlled by light}

Light is perhaps the most important consideration for optimizing plant growth, with light being utilized as both an energy source and as a developmental signal. All aspects of plant development are responsive to light, from germination through to the transition to flowering and fruit ripening 86 . The process by which developmental alterations occur in response to the changing light environment is referred to as photomorphogenesis ${ }^{6}$. In the absence of light newly-germinated seedlings have an etiolated phenotype with an extended hypocotyl (primary stem), an apical hook, and unopened cotyledons (embryonic leaves, Fig. 2a) ${ }^{86}$. These traits enable the seedling to rapidly emerge from the soil into the light at which point de-etiolation occurs, with dramatic consequences for seedling morphology. Light induces cotyledon expansion and the development of chloroplasts, thereby enabling photosynthesis, while hypocotyl elongation is curtailed. While this is perhaps the most dramatic light-induced developmental transition, light continues to be monitored throughout vegetative growth. Light intensity, duration, and spectral quality influence a range of vegetative characteristics including branching, internode elongation, leaf expansion, and orientation, with each of the photoreceptor families contributing via the photosensory network ${ }^{6,87}$. Light is also a fundamental signal necessary for the transition to flowering ${ }^{6}$, while the effects of light upon fruit development are also beginning to emerge.

Following photoperception phytochromes, cryptochromes, and UVR8, induce photomorphogenesis by inducing comprehensive changes in gene expression ${ }^{30,88}$. Much of plant photomorphogenesis is regulated via conserved modules, which are named after the originally identified components (Fig. 2). In the first module, COP1 acts with SUPPRESSOR OF PHYA (SPA) proteins to degrade a positive regulator HY5 in the dark ${ }^{89-91}$. In the presence of red or blue light, the COP1/SPA complex is inactivated by phytochromes and cryptochromes ${ }^{89,92}$, leading to the accumulation of HY5 and the induction of photomorphogenesis. Interestingly, UVR8 promotes photomorphogenesis through an alternative mechanism whereby UV-B activated UVR8 monomers associate with the COP1/SPA complex to promote HY5 accumulation ${ }^{93}$. The COP1/SPA complex also degrades CONSTANS, an essential component of the photoperiodic flowering pathway (see the section 'Photoperiodic control of flowering time'), and PIFs ${ }^{94}$. PIFs form the second regulatory hub ${ }^{94}$ and are also directly bound and inactivated by both phytochromes and cryptochromes; UVR8 indirectly inhibits PIF accumulation by repressing PIF transcription ${ }^{95-101}$. PIFs have important roles in regulating genes necessary for photomorphogenesis, but are rapidly degraded in the presence of light ${ }^{94}$. In addition, the light-induced degradation of PIFs can be limited by far-red light, thereby allowing PIFs to direct aspects of the shade avoidance response ${ }^{102,103}$. In combination, the COP1 and PIF signalling hubs integrate environmental information to control gene expression ${ }^{89,94}$.

\section{Light-induced pigments \\ Phenylpropanoids}

Fruit quality is typically dependent upon the health of the bearing plants, although direct light irradiation also alters their biochemical composition ${ }^{66}$. One of the principle determinants of fruit quality is the accumulation of phenylpropanoids (including flavonols, anthocyanins, and proanthocyanidins), which alter the color, aroma, astringency, and antioxidant properties of fruit ${ }^{104}$. Importantly, light can have dramatic effects upon the quantity and 


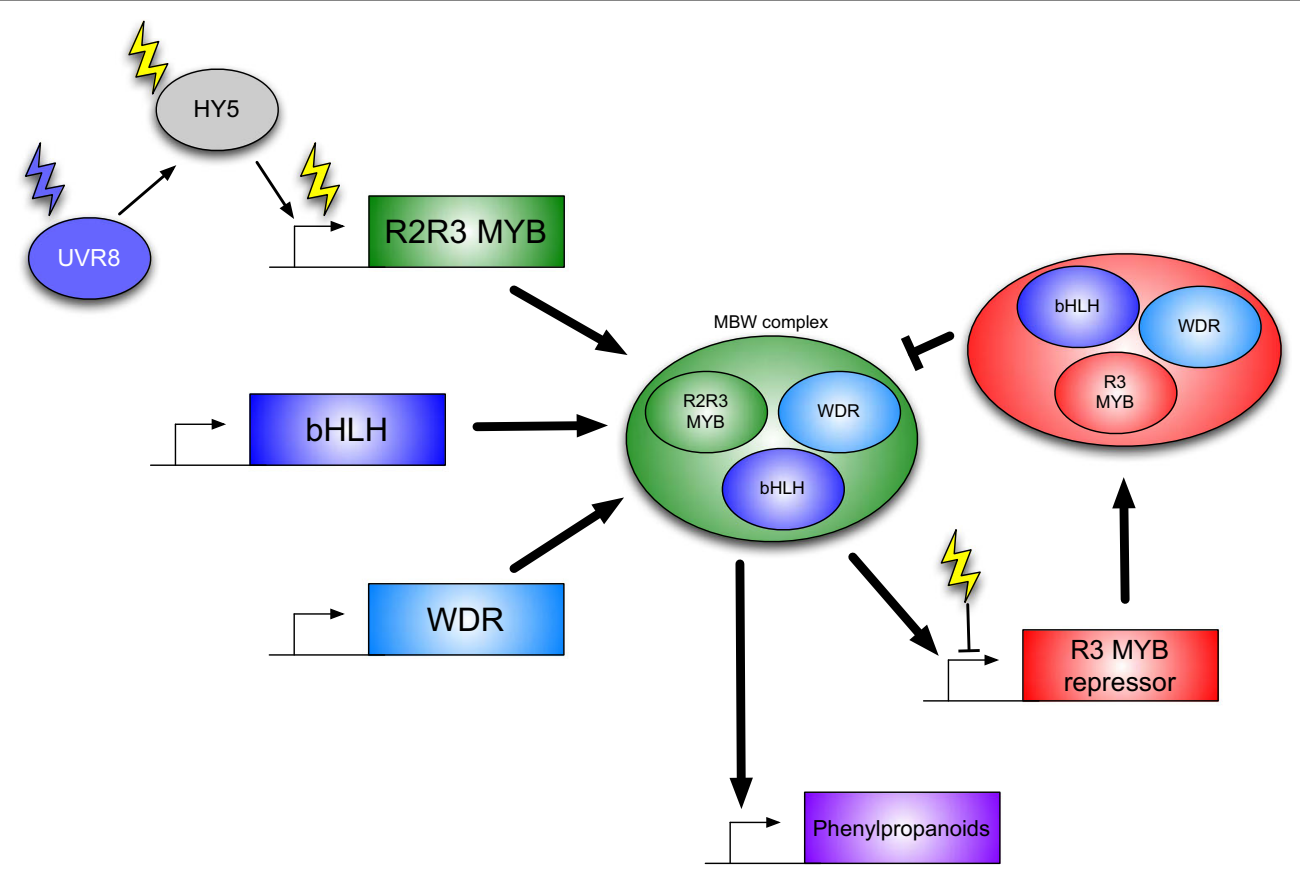

Fig. 3 Phenylpropanoids accumulation can be induced by light. Phenylpropanoid accumulation is regulated by a conserved regulatory module comprising a R2R3 MYB, a bHLH, and a WDR transcription factor. Together these three proteins comprise the MBW complex that activates transcription of enzymes necessary for phenylpropanoid production. Of these three proteins, developmental and environmental induction of R2R3 MYBs is regulated to control MBW activity, in part via the transcription factor HY5. UVR8 stabilizes HY5 through modulation of the COP1/SPA complex, while other photoreceptors promote HY5 stability indirectly or act independently of HY5 (See Fig. 2). Additional control commonly occurs via feedback loops including closely related R3 MYBs that serve to repress MBW activity. R3 MYB transcription can be regulated by the MBW itself, or be independently repressed by light or other environmental and developmental signals. Genes are represented by rectangles, proteins by ovals. Green complexes activate gene expression, red components repress MBW activity. bHLH basic HELIX LOOP HELIX, HY5 ELONGATED HYPOCOTYL5, MBW MYB/bHLH/WDR complex, UVR8 UVB RESISTANCE LOCUS8

types of flavonoids that accumulate (reviewed by ${ }^{66}$ ), although it should be noted that centuries of selective breeding have altered the specific responses of our crops (for example red vs. green apples ${ }^{105}$ ).

The spatial and temporal induction of phenylpropanoid metabolism occurs both post-transcriptionally and posttranslationally via a conserved agglomeration of R2R3 MYB, bHLH, and WDR transcription factors known as the MBW complex (Fig. $3^{66,106-109}$ ). Regulation of the MBW complex by light subsequently leads to the altered accumulation of phenylpropanoids, although additional R3 MYBs are also capable of binding to the MBW complex to limit its activity $^{110}$. For example, the R2R3 MYB transcription factor PAP1 is degraded by the COP1/SPA complex in the dark, leading to reduced anthocyanin accumulation (Figs. 2 and $3^{111}$ ), while UV-B light (via UVR8) induces transcription of R2R3 MYBs that induce flavonol accumulation in Arabidopsis and grape ${ }^{112,113}$. Interestingly, accumulation of phenylpropanoids can be increased by manipulating photoreceptor abundance in transgenic tomato and strawberry fruits, suggesting that activation of these photoreceptors using specific wavelengths of light could improve the nutritional value of fruits ${ }^{114,115}$.

\section{Carotenoids}

In addition to the regulation of phenylpropanoids, light also regulates the production of carotenoids as part of photomorphogenesis ${ }^{116,117}$. While carotenoids play a vital role in photosynthesis as part of the light harvesting complex $^{118}$, they have also been adopted as photoprotectants, and have additional roles in growth and development ${ }^{118}$. In horticulture, carotenoids are valued as a valuable source of anti-oxidants and essential dietary precursors that accumulate in fruits and vegetables as they ripen ${ }^{118,119}$.

Light has been observed to affect carotenoid biosynthesis in a number of species during fruit ripening and flower development ${ }^{120,121}$. The carotenoid biosynthetic pathway is complex, and thoroughly reviewed elsewhere $^{118}$. It is important to note, however, that one of the rate-limiting enzymes necessary for carotenoid biosynthesis, PHYTOENE SYNTHASE (PSY), is regulated by light. PSY activity is reversibly induced by red light, suggesting a role for phytochromes in this response ${ }^{122}$. It is likely that this regulation acts via COP1 (Fig. 2), as transgenic tomato fruits with reduced COP1 or HY5 transcript accumulation had altered carotenoid content ${ }^{123}$, although 


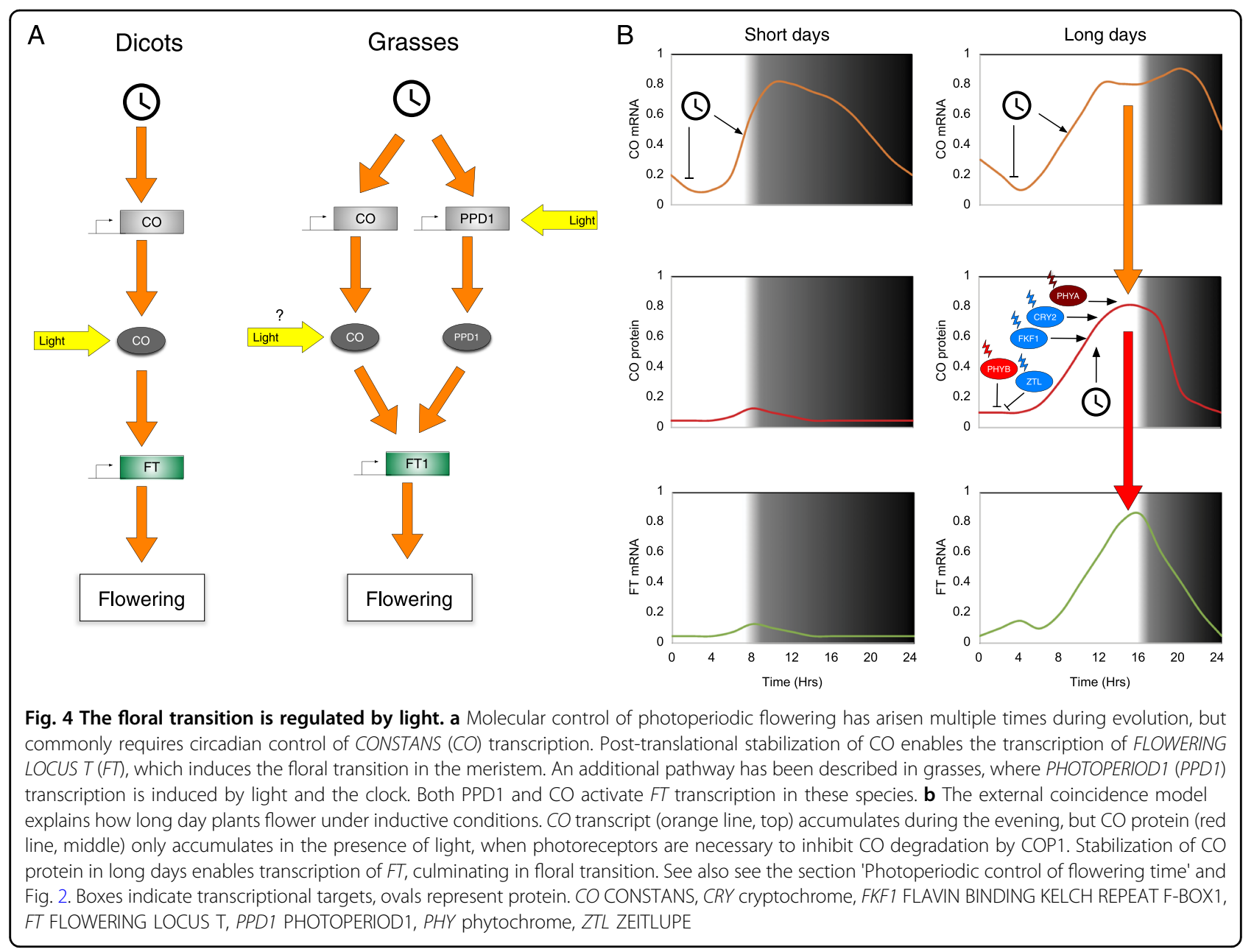

light induction of PSY transcript has also been reported in some species ${ }^{124}$. Encouragingly, studies using transgenic tomato to over-express phytochromes and cryptochromes observed increased carotenoid accumulation in transgenic fruits $^{114,125}$, suggesting that enhancement of photoreceptor signalling could be sufficient to induce carotenoid accumulation.

\section{Shade avoidance}

Modern horticulture requires plants to be grown in close proximity so as to generate a commercially-viable harvest, inevitably inducing a shade avoidance response as plants seek to outcompete their neighbors. Importantly, plants perceive and respond to changes in light quality before they are shaded, ensuring that most crops are responding to shade even if direct shading is avoi$\operatorname{ded}^{102,126}$. Plants absorb light in a wavelength-dependent manner, absorbing light in the UV and photosynthetically active portions of the spectrum (although comparatively less green) while reflecting far-red and infra-red light. As a consequence, plants are able to perceive shade as a change in either the quality or quantity of light ${ }^{102,127,128}$. Given phytochromes' sensitivity to red/far-red light (see the section 'Phytochromes'), much research regarding shade avoidance (and consequently our understanding) concerns the role of these photoreceptors in mediating this response $\mathrm{e}^{102,126}$. It is, however, important to note the role of blue, green, and UV portions of the spectra in governing plants responses to shade $e^{63,98,128}$.

Shade avoidance has many consequences for plant growth, ranging from leaf hyponasty (leaf movement), stem or petiole elongation, and directional growth away from shade of actively growing tissues, through to architectural changes such as reduced branching and increased leaf senescence that reduces resources devoted to shaded leaves ${ }^{102,129,130}$. These developmental changes ensure that plants are able to exploit any gaps in the canopy while also promoting vertical growth to over-shadow neighboring plants. Such developmental changes can also culminate in an acceleration to flowering in some species, with inactivation of phytochromes by far-red enriched light relieving repression of photoperiodic flowering 
(see the section 'Photoperiodic control of flowering time', $\left.{ }^{131-133}\right)$. In commercial applications, such behavioral changes can potentially culminate in reduced yield, or in increased crop management (e.g., pruning) to minimize these consequences ${ }^{134,135}$, although such effects can be mitigated through the choice of alternate varieties.

\section{Photoperiodic control of flowering time}

As part of the maturation process, plants undergo a transition to flowering that is largely irreversible ${ }^{136}$. The floral transition is consequently tightly regulated, with plants integrating day-length, age, and temperature cues to determine flowering time. These pathways combine to control the accumulation of FLOWERING LOCUS T (FT), which is the florigen transported from the leaves to the shoot apical meristem to initiate the floral transition in numerous species ${ }^{137,138}$. Given the importance of flowering to agriculture and horticulture, considerable time has been spent elucidating the molecular pathways underlying this control, although only light-induced pathways are considered here ${ }^{80}$.

Flowering time in response to day-length is explained by the external co-incidence model, which is conserved across a wide-range of species (Fig. $4^{80}$ ). Transcription of a transcriptional activator, CONSTANS (CO), is controlled by the circadian system so that the protein accumulates during the late afternoon ${ }^{80,137,139}$. In particular, CYCLING DOF FACTORs (CDFs) prevent transcription of $\mathrm{CO}$, but are degraded via a blue light-dependent pathway mediated by FKF1 in long days, allowing CO to accumulate under inductive conditions ${ }^{52}$. Importantly, $\mathrm{CO}$ protein is stabilized by blue or far-red light, with additional control mediated by clock-regulated factors ${ }^{140-}$ ${ }^{142}$. This light-dependent regulation ensures that $\mathrm{CO}$ only accumulates in long days, and so $F T$ transcription is limited to these permissive conditions in long day plants. Interestingly, red light limits $\mathrm{CO}$ accumulation in the morning ${ }^{140,143,144}$ suggesting that flowering may be suppressed in the absence of shade. Although Arabidopsis $\mathrm{CO}$ arose from a duplication during the divergence of the Brassicaceae, numerous examples indicate that regulation of FT by $\mathrm{CO}$ orthologues is a common consequence of convergent evolution ${ }^{145-147}$. For instance, a CO orthologue, $\mathrm{Hd} 1$, has been co-opted as a floral repressor in rice, a short day species ${ }^{148}$.

Additional photoperiodic flowering pathways have been identified in grasses such as barley and wheat (Fig. 4a). In these species PHOTOPERIOD 1 (PPD1), a gene that arose from a duplication of a circadian clock gene after the divergence of the grasses, is important to integrate circadian and photoperiod information ${ }^{149-151}$. PPD1 is expressed in the light via phytochrome $\mathrm{C}$ (phyC), and subsequently acts to promote expression of the $F T$ homologue FLOWERING LOCUS T1 (FT1 $)^{151-153}$. This pathway appears to act in addition to the CONSTANSmediated pathway, although the relationship between CO-derived and PPD1-derived pathways remains to be fully tested ${ }^{139}$. It remains to be determined whether pathways analogous to PPD1 have arisen outwith the grasses.

\section{Improving crop yield using light}

As light is a prerequisite for photosynthesis (and consequently plant growth) supplemental lighting is typically used to accelerate plant development ${ }^{154-156}$. Growers face many challenges in providing optimal lighting, with shade, cloud cover, and changing seasons introducing heterogeneity in both the spatial and temporal distribution of light. Given the broad range of light qualities perceived by plants it is apparent that at least one source of broad spectrum light should be provided (either from natural illumination, metal halide $(\mathrm{MH})$, and High Pressure Sodium (HPS) lights, or from white or multi-spectral LED arrays). Beyond this requirement, many opportunities exist to manipulate the precise light environment used for plant growth to stimulate desirable plant development (such as fruit quality or delaying flowering to promote vegetative growth).

Supplemental overhead lighting has been used in glasshouses for many years to increase crop production during periods of low natural light, either to extend shorter winter days or during periods of inclement weather ${ }^{154,156}$. In general, a $1 \%$ increase in lighting provides a $1 \%$ increase in yield, although interactions between light and other factors (such as temperature and $\mathrm{CO}_{2}$ ) complicate this relationship ${ }^{157}$. Despite these obvious opportunities, numerous studies emphasize the varied responses of different crops to supplemental lighting regimes. It is also important to note that periods of darkness are often required to prevent chlorosis or impaired leaf development ${ }^{158-162}$. As a consequence it will be important to develop light regimes optimized for specific crops, with consideration of the local natural lighting environment, rather than applying a uniform lighting regime.

\section{Supplemental lighting and spectral manipulation}

The development of LEDs that are cost effective to install at commercial scales exponentially increases the options available to growers as they seek to improve crop yield, with the opportunity to specify the quality, quantity, uniformity, and duration of light used ${ }^{163}$. LEDs also irradiate much less heat that their metal halide $(\mathrm{MH})$ and high pressure sodium (HPS) predecessors, enabling novel strategies such as intra-canopy lighting to provide more uniform light throughout the canopy. Numerous studies demonstrate the utility of supplemental lighting, with improvements in crops ranging from lettuce leaves to the 
fruits of strawberries, cucumbers, sweet peppers, and tomatoes ${ }^{164-167}$. For instance, illumination of peppers with light was sufficient to induce color break, greatly improving commercial value ${ }^{168}$, while altering the ratio of blue and red light used to irradiate lambs lettuce (Valerianella locusta) improved yield and both sugar and phenol content of harvested leaves ${ }^{165}$. The individual sensitivities of plant photoreceptor families enables plant growth and development to be precisely controlled by changing the proportion of red/far-red/blue/UV LEDs used, with these light conditions changing plant architecture and flowering via pathways summarized in the 'Plant development is controlled by light' section. In future it will be necessary to refine our understanding of photoreceptor function in crops so that light regimes (including the precise light spectra used) can be optimized to improve yield and quality.

\section{Photoperiod extension}

Perhaps the simplest utilization of supplemental lighting is to extend day length during the winter months. In some day neutral species, such as sweet peppers, day length extension photoperiod increased fruit yield, although comparable increases were not observed in closely related Solanaceae, such as tomatoes ${ }^{160}$. Interestingly, light quality has a profound effect on plant growth. For instance, the use of blue LEDs at the end of day improve tomato quality (although not yield ${ }^{169}$ ). As a consequence, it will be of great benefit to understand how photoreceptors contribute to these yield and quality phenotypes. Such knowledge will enable more a systematic approach to specifying light regimes for specific crops. This specification will depend upon both the local light environment and the qualities desired in the crop.

\section{Intracanopy lighting}

The higher energy efficiency of LEDs ensures that they are much cooler than their MH and HPS equivalents ${ }^{170}$. This allows LEDs to be interspersed within a canopy to ensure greater light distribution throughout a densely planted crop. This has multiple benefits, ranging from greater light use efficiency (and therefore reduced energy consumption ${ }^{171}$ ), to increase uniformity, quality, and yield of fruit ${ }^{166,167}$. Intracanopy lighting could also be used to control plant architecture; for instance supplemental red light could be used to minimize internode elongation and leaf drop as part of a shade avoidance response. This has particular relevance for leaf crops such as lettuce, where supplemental lighting has been used to limit senescence, thereby enhancing yield ${ }^{172}$.

\section{Night breaks}

Beyond the utilization of supplemental lighting to extend day length and increase the distribution of light in the canopy, short periods of light during the night have been successfully used to manipulate plant development. In short day plants, such as Chrysanthemum and Ipomoea nil, night breaks using red light can be used to delay flowering ${ }^{173-175}$. Conversely, night breaks can be used to accelerate flowering in long day plants ${ }^{176}$. In tomato, red light night breaks induced a delay in flowering and decreased plant height while also improving tomato fresh weigh shortly after flowering ${ }^{177}$. These differences in flowering and plant morphology are most likely derived from activation of phytochromes (which would otherwise revert to their inactive state in the dark-see the section 'Phytochromes') and it is likely such phenomena will also be observed in other species.

\section{Post-harvest lighting regimes}

Supplemental lighting can also be used after harvesting to prolong shelf-life or to alter the biochemical properties of the crop. For instance, irradiation with white LEDs was sufficient to delay senescence and therefore promote the shelf life of harvested sprouts ${ }^{178}$, whereas irradiation of sweet peppers after harvesting was sufficient to induce color break, thereby enhancing market value ${ }^{179}$. Interestingly, maintenance of circadian rhythms through the utilization of light:dark cycles delays senescence compared to constantly lit conditions, demonstrating the need for further research to more thoroughly understand how complex lighting regimes can be utilized to improve storage of harvested crops $^{180}$.

\section{Future perspectives}

Plants have evolved a sophisticated network of photoreceptors that enable them to perceive and respond to environmental change. As commercial scale installation of LEDs becomes viable, the on-going challenge facing commercial growers will be the optimization of lighting regimes to promote desirable qualities for glasshouse management and crop quality, while also considering the economic costs of LED installation and the specific photoresponsive traits of their crop. Although there are numerous examples of diversification of regulatory pathways, it is reassuring that the photoreceptors and key downstream regulatory modules regulating flowering time, phenylpropanoid biosynthesis, and carotenoid production are conserved. Such conservation demonstrates that it will be possible to utilize the understanding gained from model species to design tailored light regimes optimized for many glasshouse-grown crops, leading to improved yield and quality in the future.

Acknowledgements

The author thanks the University of Essex for funding this work.

Conflict of interest

The author declares that he has no conflict of interest. 
Received: 20 February 2018 Revised: 24 April 2018 Accepted: 2 May 2018 Published online: 01 September 2018

\section{References}

1. Cooper, A. J. Observations on the seasonal trends in the growth of the leaves and fruit of glasshouse tomato plants, considered in relation to light duration and plant age. J. Hortic. Sci. 36, 55-69 (1961).

2. Darko, E., Heydarizadeh, P., Schoefs, B. \& Sabzalian, M. R. Photosynthesis under artificial light: the shift in primary and secondary metabolism. Philos. Trans. R. Soc. Lond. B. Biol. Sci. 369, 20130243 (2014).

3. Yang, L. Y. et al. Effects of light quality on growth and development, photosynthetic characteristics and content of carbohydrates in tobacco (Nicotiana tabacum L.) plants. Photosynthetica 55, 467-477 (2017).

4. Jones, M. A. Interplay of circadian rhythms and light in the regulation of photosynthesis-derived metabolism. Progress. Bot. 79, 147-171 (2017).

5. Li, J., Terzaghi, W. \& Deng, X. W. Genomic basis for light control of plant development. Protein Cell 3, 106-116 (2012).

6. Whitelam, G. C. \& Halliday, K. J. Light and Plant Development. Annual Plant Reviews 30 (Blackwell Publishing, UK, 2007).

7. Briggs, W. R. \& Spudich, J. L. Handbook of Photosensory Receptors. (Wiley-VCH, Germany, 2005).

8. Rockwell, N. C., Su, Y.-S. \& Lagarias, J. C. Phytochrome structure and signalling mechanisms. Annu. Rev. Plant. Biol. 57, 837-858 (2006).

9. Christie, J. M., Blackwood, L., Petersen, J. \& Sullivan, S. Plant flavoprotein photoreceptors. Plant Cell Phys. 56, 401-413 (2015).

10. Li, Q.-H. \& Yang, H.-Q. Cryptochrome signaling in plants. Photochem. Photobiol. 83, 94-101 (2007).

11. Briggs, W. R. The LOV domain: a chromophore module servicing multiple photoreceptors. J. Biomed. Sci. 14, 499-504 (2007).

12. Jenkins, G. I. Photomorphogenic responses to ultraviolet-B light. Plant, Cell Environ. 40, 2544-2557 (2017).

13. Wang, Y. \& Folta, K. M. Contributions of green light to plant growth and development. Am. J. Bot. 100, 70-78 (2013).

14. Butler, W. L., Norris, K. H., Seigelman, H. W. \& Hendricks, S. B. Detection, assay and preliminary purification of the pigment controlling photoresponsive development of plants. Proc. Natl Acad. Sci. USA 45, 1703-1708 (1959).

15. Rockwell, N. C., Su, Y.-S. \& Lagarias, J. C. Phytochrome structure and signaling mechanisms. Annu. Rev. Plant. Biol. 57, 837-858 (2006).

16. Huq, E. \& Quail, P. H. in Handbook of Photosensory Receptors (eds W. R. Briggs \& J. L. Spudich) Ch. 7, 151-170 (Wiley-VCH, Germany, 2005).

17. Mathews, S., \& Sharrock, R. A. Phytochrome gene diversity. Plant Cell \& Environment 20, 666-671 (1997).

18. Casal, J. J., Yanovsky, M. J. \& Luppi, J. P. Two photobiological pathways of phytochrome A activity, only one of which shows dominant negative suppression by phytochrome B. Photochem. Photobiol. 71, 481-486 (2000).

19. Sharrock, R. A. \& Clack, T. Patterns of expression and normalized levels of the five arabidopsis phytochromes. Plant Physiol. 130, 442-456 (2002).

20. Franklin, K. A., Larner, V. S. \& Whitelam, G. C. The signal transducing photoreceptors of plants. Int. J. Dev. Biol. 49, 653-664 (2005).

21. Schafer, E. \& Bowler, C. Phytochrome-mediated photoperception and signal transduction in higher plants. EMBO Rep. 3, 1042-1048 (2002).

22. Daiyasu, $\mathrm{H}$. et al. Identification of cryptochrome DASH from vertebrates. Genes Cells 9, 479-495 (2004).

23. Lin, C., Ahmad, M., Chan, J. \& Cashmore, A. R. CRY2, a second member of the Arabidopsis cryptochrome gene family (accession No. U43397) (PGR 96-001). Plant Physiol. 110, 1047 (1996).

24. Kleine, T., Lockhart, P. \& Batschauer, A. An Arabidopsis protein closely related to Synechocystis cryptochrome is targeted to organelles. Plant J. 35, 93-103 (2003).

25. Ahmad, M. \& Cashmore, A. R. HY4 gene of A. thaliana encodes a protein with characteristics of a blue-light photoreceptor. Nature 366, 162-166 (1993).

26. Chaves, I. et al. The cryptochromes: blue light photoreceptors in plants and animals. Annu. Rev. Plant. Biol. 62, 335-364 (2011).

27. Wang, Q. et al. Photoactivation and inactivation of Arabidopsis cryptochrome 2. Science 354, 343-347 (2016).

28. Lin, C. et al. Enhancement of blue-light sensitivity of Arabidopsis seedlings by a blue light receptor cryptochrome 2. Proc. Natl Acad. Sci. USA 95, 2686-2690 (1998).

29. $\mathrm{Yu}, \mathrm{X}$. et al. Arabidopsis cryptochrome 2 completes its posttranslational life cycle in the nucleus. Plant Cell 19, 3146-3156 (2007).
30. Ma, L. et al. Light control of Arabidopsis development entails coordinated regulation of genome expression and cellular pathways. Plant Cell 13, 2589-2607 (2001).

31. Jiao, Y. et al. A genome-wide analysis of blue-light regulation of Arabidopsis transcription factor gene expression during seedling development. Plant Physiol. 133, 1480-1493 (2003).

32. Ahmad, M., Lin, C. \& Cashmore, A. R. Mutations throughout an Arabidopsis blue-light photoreceptor impair blue-light-responsive anthocyanin accumulation and inhibition of hypocotyl elongation. Plant J. 8, 653-658 (1995).

33. Liu, $\mathrm{H}$. et al. Photoexcited $\mathrm{CRY} 2$ interacts with $\mathrm{CIB} 1$ to regulate transcription and floral initiation in Arabidopsis. Science 322, 1535-1539 (2008).

34. Liu, H., Liu, B., Zhao, C., Pepper, M. \& Lin, C. The action mechanisms of plant cryptochromes. Trends Plant Sci. 16, 684-691 (2011).

35. Gallagher, S., Short, T. W., Ray, P. M., Pratt, L. H. \& Briggs, W. R. Light-mediated changes in two proteins found associated with plasma membrane fractions from pea stem sections. Proc. Natl Acad. Sci. USA 85, 8003-8007 (1988).

36. Huala, E. et al. Arabidopsis NPH1: a protein kinase with a putative redoxsensing domain. Science 278, 2120-2123 (1997).

37. Briggs, W. R. et al. The phototropin family of photoreceptors. Plant Cell 13, 993-997 (2001).

38. Briggs, W. R., Christie, J. M. \& Salomon, M. Phototropins: a new family of flavin-binding blue light receptors in plants. Antioxid. Redox Signal. 3, 775-788 (2001).

39. Kagawa, T. et al. Arabidopsis NPL1: a phototropin homolog controlling the chloroplast high-light avoidance response. Science 291, 2138-2141 (2001).

40. Briggs, W. R. \& Christie, J. M. Phototropins 1 and 2: versatile plant blue-light receptors. Trends Plant Sci. 7, 204-210 (2002).

41. Ohgishi, M., Saji, K., Okada, K. \& Sakai, T. Functional analysis of each blue light receptor, cry1, cry2, phot1, and phot2, by using combinatorial multiple mutants in Arabidopsis. Proc. Natl Acad. Sci. USA 101, 2223-2228 (2004).

42. Christie, J. M. Phototropin blue-light receptors. Annu. Rev. Plant. Biol. 58 21-45 (2007).

43. Lariguet, P. \& Dunand, C. Plant photoreceptors: phylogenetic overview. J. Mol. Evol. 61, 559-569 (2005).

44. Huang, K., Merkle, T. \& Beck, C. F. Isolation and characterization of a Chlamydomonas gene that encodes a putative blue-light photoreceptor of the phototropin family. Physiol. Plant. 115, 613-622 (2002).

45. Nozue, K. et al. A phytochrome from the fern Adiantum with features of the putative photoreceptor NPH1. Proc. Natl Acad. Sci. USA 95, 15826-15830 (1998).

46. Suetsugu, N., Mittmann, F., Wagner, G., Hughes, J. \& Wada, M. A chimeric photoreceptor gene, NEOCHROME, has arisen twice during plant evolution. Proc. Natl Acad. Sci. USA 102, 13705-13709 (2005).

47. Kawai, H. et al. Responses of ferns to red light are mediated by an unconventional photoreceptor. Nature 421, 287-290 (2003).

48. Somers, D. E., Schultz, T. F., Milnamow, M. \& Kay, S. A. ZEITLUPE encodes a novel clock-associated PAS protein from Arabidopsis. Cell 101, 319-329 (2000).

49. Nelson, D. C., Lasswell, J., Rogg, L. E., Cohen, M. A. \& Bartel, B. FKF1, a clockcontrolled gene that regulates the transition to flowering in Arabidopsis. Cell 101, 331-340 (2000).

50. Schultz, T. F., Kiyosue, T., Yanovsky, M., Wada, M. \& Kay, S. A. A role for LKP2 in the circadian clock of Arabidopsis. Plant Cell 13, 2659-2670 (2001).

51. Somers, D. E. Clock-associated genes in Arabidopsis: a family affair. Philos. Trans. R. Soc. Lond. B. Biol. Sci. 356, 1745-1753 (2001).

52. Sawa, M., Nusinow, D. A., Kay, S. A. \& Imaizumi, T. FKF1 and GIGANTEA complex formation is required for day-length measurement in Arabidopsis. Science 318, 261-265 (2007).

53. Kim, W. Y. et al. ZEITLUPE is a circadian photoreceptor stabilized by GIGANTEA in blue light. Nature 449, 356-360 (2007).

54. Song, Y. H. et al. Distinct roles of FKF1, Gigantea, and Zeitlupe proteins in the regulation of constans stability in Arabidopsis photoperiodic flowering. Proc Natl Acad. Sci. USA 111, 17672-17677 (2014)

55. Imaizumi, T., Schultz, T. F., Harmon, F. G., Ho, L. A. \& Kay, S. A. FKF1 F-box protein mediates cyclic degradation of a repressor of CONSTANS in Arabidopsis. Science 309, 293-296 (2005).

56. Tilbrook, K. et al. The UVR8 UV-B photoreceptor: perception, signaling and response. The Arabidopsis book /Am Soc Plant Biologists 11, e0164 (2013).

57. Rizzini, L. et al. Perception of UV-B by the Arabidopsis UVR8 protein. Science 332, 103-106 (2011). 
58. Wu, D. et al. Structural basis of ultraviolet-B perception by UVR8. Nature $\mathbf{4 8 4}$, 214-219 (2012).

59. Kliebenstein, D. J., Lim, J. E., Landry, L. G. \& Last, R. L. Arabidopsis UVR8 regulates ultraviolet- $B$ signal transduction and tolerance and contains sequence similarity to human regulator of chromatin condensation 1. Plant Physiol. 130, 234-243 (2002).

60. Liang, T. et al. UVR8 Interacts with BES1 and BIM1 to regulate transcription and photomorphogenesis in Arabidopsis. Dev. Cell 44, 512-523.e515 (2018).

61. Yang, Y. et al. UVR8 interacts with WRKY36 to regulate HY5 transcription and hypocotyl elongation in Arabidopsis. Nat. Plants 4, 98-107 (2018).

62. Brown, B. A. \& Jenkins, G. I. UV-B signaling pathways with different fluencerate response profiles are distinguished in mature Arabidopsis leaf tissue by requirement for UVR8, HY5, and HYH. Plant Physiol. 146, 576-588 (2008).

63. Favory, J.-J. et al. Interaction of COP1 and UVR8 regulates UV-B-induced photomorphogenesis and stress acclimation in Arabidopsis. EMBO J. 28, 591-601 (2009).

64. Wargent, J. J. \& Jordan, B. R. From ozone depletion to agriculture: understanding the role of UV radiation in sustainable crop production. New Phytol. 197, 1058-1076 (2013).

65. Ballaré, C. L., Mazza, C. A., Austin, A. T. \& Pierik, R. Canopy light and plant health. Plant Physiol. 160, 145-155 (2012).

66. Zoratti, L., Karppinen, K., Luengo Escobar, A., Häggman, H. \& Jaakola, L. Lightcontrolled flavonoid biosynthesis in fruits. Front. Plant Sci. 5, 534 (2014).

67. Davey, M. P. et al. The UV-B photoreceptor UVR8 promotes photosynthetic efficiency in Arabidopsis thaliana exposed to elevated levels of UV-B. Photo. Res. 114, 121-131 (2012).

68. Moriconi, V. et al. Perception of sunflecks by the UV-B photoreceptor UV RESISTANCE LOCUS 8. Plant Physiol., https://doi.org/10.1104/pp.18.00048 (2018).

69. Wigge, P. A. Ambient temperature signalling in plants. Curr. Opin. Plant Biol. 16, 661-666 (2013)

70. Quint, M. et al. Molecular and genetic control of plant thermomorphogenesis. Nat. Plants 2, 15190 (2016).

71. Jung, J.-H. et al. Phytochromes function as thermosensors in Arabidopsis. Science 354, 886-889 (2016).

72. Legris, M. et al. Phytochrome B integrates light and temperature signals in Arabidopsis. Science 354, 897-900 (2016)

73. Fujii, Y. et al. Phototropin perceives temperature based on the lifetime of its photoactivated state. Proc. Natl Acad. Sci. USA 114, 9206-9211 (2017).

74. Jones, M. Entrainment of the Arabidopsis circadian clock. J. Plant Biol. 52 , 202-209 (2009).

75. Hsu, P. Y. \& Harmer, S. L. Wheels within wheels: the plant circadian system. Trends Plant Sci. 19, 240-249 (2014).

76. Covington, M. F., Maloof, J. N., Straume, M., Kay, S. A. \& Harmer, S. L. Global transcriptome analysis reveals circadian regulation of key pathways in plant growth and development. Genome Biol. 9, R130 (2008).

77. Tóth, R. et al. Circadian clock-regulated expression of phytochrome and cryptochrome genes in Arabidopsis. Plant Physiol. 127, 1607-1616 (2001).

78. Mockler, T. et al. The DIURNAL project: DIURNAL and circadian expression profiling, model-based pattern matching, and promoter analysis. Cold Spring Harb. Symp. Quant. Biol. 72, 353-363 (2007).

79. Millar, A. J. Input signals to the plant circadian clock. J. Exp. Bot. 55, 277-283 (2004).

80. Song, Y. H., Shim, J. S., Kinmonth-Schultz, H. A. \& Imaizumi, T. Photoperiodic flowering: time measurement mechanisms in leaves. Annu. Rev. Plant Biol. 66, 441-464 (2015).

81. Devlin, P. \& Kay, S. Cryptochromes are required for phytochrome signaling to the circadian clock but not for rhythmicity. Plant Cell 12, 2499-2510 (2000).

82. Somers, D., Devlin, P. \& Kay, S. Phytochromes and cryptochromes in the entrainment of the Arabidopsis circadian clock. Science 282, 1488-1490 (1998).

83. Jones, M., Hu, W., Litthauer, S., Lagarias, J. C. \& Harmer, S. L. A constitutively active allele of phytochrome $B$ maintains circadian robustness in the absence of light. Plant Physiol. 169, 814-825 (2015).

84. Baudry, A. et al. F-box proteins FKF1 and LKP2 act in concert with ZEITLUPE to control Arabidopsis clock progression. Plant Cell 22, 606-622 (2010).

85. Wang, L., Fujiwara, S. \& Somers, D. E. PRR5 regulates phosphorylation, nuclear import and subnuclear localization of TOC1 in the Arabidopsis circadian clock. EMBO J. 29, 1903-1915 (2010).

86. Fankhauser, C. \& Chory, J. Light control of plant development. Annu. Rev. Cell Dev. Biol. 13, 203-229 (1997).
87. Leduc, N. et al. Light signaling in bud outgrowth and branching in plants. Plants 3, 223-250 (2014).

88. Brown, B. A. et al. A UV-B-specific signaling component orchestrates plant UV protection. Proc. Natl Acad. Sci. USA 102, 18225-18230 (2005).

89. Lau, O.-S. \& Deng, X. W. The photomorphogenic repressors COP1 and DET1: 20 years later. Trends Plant Sci. 17, 584-593 (2012).

90. Osterlund, M. T., Hardtke, C. S., Wei, N. \& Deng, X. W. Targeted destabilization of HY5 during light-regulated development of Arabidopsis. Nature 405, 462-466 (2000).

91. Laubinger, S., Fittinghoff, K. \& Hoecker, U. The SPA quartet: a family of WDrepeat proteins with a central role in suppression of photomorphogenesis in Arabidopsis. Plant Cell 16, 2293-2306 (2004).

92. Yi, C. \& Deng, X. W. COP1 - from plant photomorphogenesis to mammalian tumorigenesis. Trends Cell Biol. 15, 618-625 (2005).

93. Huang, X. et al. Conversion from CUL4-based COP1-SPA E3 apparatus to UVR8-COP1-SPA complexes underlies a distinct biochemical function of COP1 under UV-B. Proc. Natl Acad. Sci. USA 110, 16669-16674 (2013).

94. Leivar, P. \& Monte, E. PIFs: systems integrators in plant development. Plant Cell 26, 56-78 (2014).

95. Kikis, E. A., Oka, Y., Hudson, M. E., Nagatani, A. \& Quail, P. H. Residues clustered in the light-sensing knot of phytochrome B are necessary for conformer-specific binding to signaling partner PIF3. PLoS Genet. 5, e1000352 (2009).

96. Oka, Y., Matsushita, T., Mochizuki, N., Quail, P. H. \& Nagatani, A. Mutant screen distinguishes between residues necessary for light-signal perception and signal transfer by phytochrome B. PLoS Genet. 4, e1000158 (2008).

97. Oka, Y. et al. Functional analysis of a 450-amino acid N-terminal fragment of phytochrome B in Arabidopsis. Plant Cell 16, 2104-2116 (2004).

98. Pedmale, U. V. et al. Cryptochromes interact directly with PIFs to control plant growth in limiting blue light. Cell 164, 233-245 (2016).

99. $\mathrm{Ma}, \mathrm{D}$. et al. Cryptochrome 1 interacts with PIF4 to regulate high temperature-mediated hypocotyl elongation in response to blue light. Proc Natl Acad. Sci. USA 113, 224-229 (2016).

100. Ni, W. et al. A mutually assured destruction mechanism attenuates light signaling in Arabidopsis. Science 344, 1160-1164 (2014).

101. Hayes, S. et al. UV-B perceived by the UVR8 photoreceptor inhibits plant thermomorphogenesis. Curr. Biol. 27, 120-127 (2017).

102. Casal, J. J. Photoreceptor signaling networks in plant responses to shade. Annu. Rev. Plant Biol. 64, 403-427 (2013).

103. Leivar, P. \& Quail, P. H. PIFs: pivotal components in a cellular signaling hub. Trends Plant Sci. 16, 19-28 (2011).

104. He, J. \& Giusti, M. M. Anthocyanins: natural colorants with health-promoting properties. Annu. Rev. Food Sci. Technol. 1, 163-187 (2010).

105. Feng, F., Li, M., Ma, F. \& Cheng, L. Phenylpropanoid metabolites and expression of key genes involved in anthocyanin biosynthesis in the shaded peel of apple fruit in response to sun exposure. Plant Physiol. Biochem. 69, 54-61 (2013).

106. Albert, N. W. et al. A conserved network of transcriptional activators and repressors regulates anthocyanin pigmentation in eudicots. Plant Cell 26, 962-980 (2014).

107. Liu, J., Osbourn, A. \& Ma, P. MYB transcription factors as regulators of phenylpropanoid metabolism in plants. Mol. Plant 8, 689-708 (2015).

108. Feller, A., Machemer, K., Braun, E. L. \& Grotewold, E. Evolutionary and comparative analysis of MYB and bHLH plant transcription factors. Plant J. 66, 94-116 (2011).

109. Quattrocchio, F., Wing, J. F., van der Woude, K, Mol, J. N. \& Koes, R. Analysis of $\mathrm{bH} L \mathrm{H}$ and MYB domain proteins: species-specific regulatory differences are caused by divergent evolution of target anthocyanin genes. Plant J. 13, 475-488 (1998).

110. Xu, W., Dubos, C. \& Lepiniec, L. Transcriptional control of flavonoid biosynthesis by MYB-bHLH-WDR complexes. Trends Plant Sci. 20, 176-185 (2015).

111. Maier, A. et al. Light and the E3 ubiquitin ligase COP1/SPA control the protein stability of the MYB transcription factors PAP1 and PAP2 involved in anthocyanin accumulation in Arabidopsis. Plant J. 74, 638-651 (2013).

112. Stracke, R. et al. The Arabidopsis bZIP transcription factor HY5 regulates expression of the PFG1/MYB12 gene in response to light and ultraviolet- $B$ radiation. Plant, Cell Environ. 33, 88-103 (2010).

113. Liu, L., Gregan, S., Winefield, C. \& Jordan, B. From UVR8 to flavonol synthase: UV-B-induced gene expression in Sauvignon blanc grape berry. Plant, Cell Environ. 38, 905-919 (2014). 
114. Giliberto, L. et al. Manipulation of the blue light photoreceptor cryptochrome 2 in tomato affects vegetative development, flowering time, and fruit antioxidant content. Plant Physiol. 137, 199-208 (2005).

115. Kadomura-Ishikawa, Y., Miyawaki, K., Noji, S. \& Takahashi, A. Phototropin 2 is involved in blue light-induced anthocyanin accumulation in Fragaria $\mathrm{X}$ ananassa fruits. J. Plant Res. 126, 847-857 (2013).

116. Welsch, R., Beyer, P., Hugueney, P., Kleinig, H. \& von Lintig, J. Regulation and activation of phytoene synthase, a key enzyme in carotenoid biosynthesis, during photomorphogenesis. Planta 211, 846-854 (2000).

117. Meier, S., Tzfadia, O., Vallabhaneni, R., Gehring, C. \& Wurtzel, E. T. A transcriptional analysis of carotenoid, chlorophyll and plastidial isoprenoid biosynthesis genes during development and osmotic stress responses in Arabidopsis thaliana. BMC Syst. Biol. 5, 77 (2011).

118. Nisar, N., Li, L., Lu, S., Khin, N. C. \& Pogson, B. J. Carotenoid metabolism in plants. Mol. Plant 8, 68-82 (2015).

119. Grierson, D., Purton, M., Knapp, J. \& Bathgate, B. Tomato Developmental Mutants (H. Thomas \& D. Grierson eds) 77-94 (Cambridge University Press, 1987).

120. Giovannoni, J. J. Genetic regulation of fruit development and ripening. Plant Cell 16, (S170-180 (2004).

121. Adams-Phillips, L., Barry, C. \& Giovannoni, J. Signal transduction systems regulating fruit ripening. Trends Plant Sci. 9, 331-338 (2004).

122. Schofield, A. \& Paliyath, G. Modulation of carotenoid biosynthesis during tomato fruit ripening through phytochrome regulation of phytoene synthase activity. Plant Physiol. Biochem. 43, 1052-1060 (2005).

123. Liu, Y. et al. Manipulation of light signal transduction as a means of modifying fruit nutritional quality in tomato. Proc. Natl Acad. Sci. USA 101, 9897-9902 (2004).

124. von Lintig, J. et al. Light-dependent regulation of carotenoid biosynthesis occurs at the level of phytoene synthase expression and is mediated by phytochrome in Sinapis alba and Arabidopsis thaliana seedlings. Plant J. 12, 625-634 (1997)

125. Boylan, M. T. \& Quail, P. H. Oat phytochrome is biologically active in transgenic tomatoes. Plant Cell 1, 765-773 (1989).

126. Casal, J. J. Shade avoidance. Arab. Book /Am. Soc. Plant Biol. 10, e0157 (2012).

127. Ballare, C. L., scopel, A. L. \& Sanchez, R. A. Photocontrol of stem elongation in plant neighbourhoods: effects of photon fluence rate under natural conditions of radiation. Plant, Cell Environ. 14, 57-65 (1991).

128. Zhang, T., Maruhnich, S. A. \& Folta, K. M. Green light induces shade avoidance symptoms. Plant Physiol. 157, 1528-1536 (2011).

129. Finlayson, S. A., Krishnareddy, S. R., Kebrom, T. H. \& Casal, J. J. Phytochrome regulation of branching in Arabidopsis. Plant Physiol. 152, 1914-1927 (2010).

130. Rousseaux, M. C., Hall, A. J. \& sanchez, rA. Far-red enrichment and photosynthetically active radiation level influence leaf senescence in field-grown sunflower. Physiol. Plant 96, 217-224 (1996).

131. Wollenberg, A. C., Strasser, B., Cerdán, P. D. \& Amasino, R. M. Acceleration of flowering during shade avoidance in Arabidopsis alters the balance between FLOWERING LOCUS C-mediated repression and photoperiodic induction of flowering. Plant Physiol. 148, 1681-1694 (2008).

132. Cerdán, P. D. \& Chory, J. Regulation of flowering time by light quality. Nature 423, 881-885 (2003).

133. Endo, M., Nakamura, S., Araki, T., Mochizuki, N. \& Nagatani, A. Phytochrome B in the mesophyll delays flowering by suppressing FLOWERING LOCUS T expression in Arabidopsis vascular bundles. Plant Cell 17, 1941-1952 (2005).

134. Ugarte, C. C., Trupkin, S. A., Ghiglione, H., Slafer, G. \& Casal, J. J. Low red/far-red ratios delay spike and stem growth in wheat. J. Exp. Bot. 61, 3151-3162 (2010).

135. Libenson, S., Rodriguez, V. M., Lopez Pereira, M., Sanchez, R. A. \& Casal, J. J. Low-Red-to-far-red-ratios-reaching-the-stem-reduce-grain-yield-in-sunflower. Crop Sci. 42, 1180-1185 (2002).

136. Evans, L. T. Flower induction and the Florigen concept. Annu. Rev. Plant Physiol. 22, 265-394 (1971).

137. Turck, F., Fornara, F. \& Coupland, G. Regulation and identity of florigen: FLOWERING LOCUS T moves center stage. Annu. Rev. Plant Biol. 59, 573-594 (2008).

138. Wickland, D. P. \& Hanzawa, Y. The FLOWERING LOCUS T/TERMINAL FLOWER 1 gene family: functional evolution and molecular mechanisms. Mol. Plant $\mathbf{8}$ 983-997 (2015).
139. Mulki, M. A. \& von Korff, M. CONSTANS controls floral repression by upregulating VERNALIZATION2 (VRN-H2) in barley. Plant Physiol. 170, 325-337 (2016).

140. Valverde, F. et al. Photoreceptor regulation of CONSTANS protein in photoperiodic flowering. Science 303, 1003-1006 (2004).

141. Zuo, Z., Liu, H., Liu, B., Liu, X. \& Lin, C. Blue light-dependent interaction of CRY2 with SPA1 regulates COP1 activity and floral initiation in Arabidopsis. Curr. Biol. 21, 841-847 (2011).

142. Hayama, R. et al. PSEUDO RESPONSE REGULATORs stabilize CONSTANS protein to promote flowering in response to day length. EMBO J. 36, 904-918 (2017).

143. Jang, S. et al. Arabidopsis COP1 shapes the temporal pattern of CO accumulation conferring a photoperiodic flowering response. EMBO J. 27, 1277-1288 (2008).

144. Lazaro, A., Mouriz, A., Piñeiro, M. \& Jarillo, J. A. Red light-mediated degradation of CONSTANS by the E3 ubiquitin ligase HOS1 regulates photoperiodic flowering in Arabidopsis. Plant Cell 27, 2437-2454 (2015).

145. Kurokura, T., Samad, S., Koskela, E., Mouhu, K. \& Hytönen, T. Fragaria vesca CONSTANS controls photoperiodic flowering and vegetative development. J. Exp. Bot. 68, 4839-4850 (2017).

146. Simon, S., Rühl, M., de Montaigu, A., Wötzel, S. \& Coupland, G. Evolution of CONSTANS regulation and function after gene duplication produced a photoperiodic flowering switch in the brassicaceae. Mol. Biol. Evol. 32, 2284-2301 (2015).

147. Liu, X. L., Covington, M. F., Fankhauser, C., Chory, J. \& Wagner, D. R. ELF3 encodes a circadian clock-regulated nuclear protein that functions in an Arabidopsis PHYB signal transduction pathway. Plant Cell 13, 1293-1304 (2001).

148. Yano, M. et al. Hd1, a major photoperiod sensitivity quantitative trait locus in rice, is closely related to the Arabidopsis flowering time gene CONSTANS Plant Cell 12, 2473-2484 (2000).

149. Farré, E. M. \& Liu, T. The PRR family of transcriptional regulators reflects the complexity and evolution of plant circadian clocks. Curr. Opin. Plant Biol. 16 621-629 (2013).

150. Turner, A. The pseudo-response regulator Ppd-H1 provides adaptation to photoperiod in barley. Science 310, 1031-1034 (2005).

151. Chen, A. et al. Phytochrome $C$ plays a major role in the acceleration of wheat flowering under long-day photoperiod. Proc. Natl Acad. Sci. USA 111 10037-10044 (2014).

152. Shaw, L. M., Turner, A. S. \& Laurie, D. A. The impact of photoperiod insensitive Ppd-1a mutations on the photoperiod pathway across the three genomes of hexaploid wheat (Triticum aestivum). Plant J. 71, 71-84 (2012).

153. Nishida, $\mathrm{H}$. et al. Phytochrome $\mathrm{C}$ is a key factor controlling long-day flowering in barley. Plant Physiol. 163, 804-814 (2013).

154. Heuvelink, E. et al. Acta Horticulturae. (International Society for Horticultural Science (ISHS), Leuven, Belgium, 2006; 25-34.

155. Hao, X. \& Papadopoulos, A. P. Effects of supplemental lighting and cover materials on growth, photosynthesis, biomass partitioning, early yield and quality of greenhouse cucumber. Sci. Hortic. 80, 1-18 (1999).

156. Lu, N. \& Mitchell, C. A. Vol. 956 LED Lighting for Urban Agriculture (T. kozai ed) 219-232 (Springer Singapore, 2016).

157. Marcelis, L. F. M. et al. Quantification of the growth response to light quantity of greenhouse grown crops. Acta Hortic. 711, 97-104 (2006).

158. Demers, D.-A., Gosselin, A.\& Wien, H. C. Effects of supplemental light duration on greenhouse sweet pepper plants and fruit yields. J. Am. Soc. Hort. Sci. 123 202-207 (1998).

159. Nilwik, H. J. M. Growth analysis of sweet pepper (Capsicum annuum L.) 2. Interacting effects of irradiance, temperature and plant age in controlled conditions. Ann. Bot. 48, 137-145 (1981).

160. Dorais, M., Yelle, S. \& Gosselin, A. Influence of extended photoperiod on photosynthate partitioning and export in tomato and pepper plants. N.Z. J. Crop Hortic. Sci. 24, 29-37 (1996).

161. Logendra, S., Putman, J. D. \& Janes, H. W. The influence of light period on carbon partitioning, translocation and growth in tomato. Sci. Hortic. 42, 75-83 (1990).

162. Vézina, F., Trudel, M. J. \& Gosselin, A. Influence du mode d'utilisation de l'éclairage d'appoint sur la productivité et la physiologie de la tomate de serre. Can. J. Plant Sci. 71, 923-932 (1991).

163. Nelson, J. A. \& Bugbee, B. Economic analysis of greenhouse lighting: light emitting diodes vs. high intensity discharge fixtures. PLOS ONE 9, e99010 (2014). 
164. Choi, H. G., Moon, B. Y. \& Kang, N. J. Effects of LED light on the production of strawberry during cultivation in a plastic greenhouse and in a growth chamber. Sci. Hortic. 189, 22-31 (2015).

165. Wojciechowska, R., Długosz-Grochowska, O., Kołton, A. \& Żupnik, M. Effects of LED supplemental lighting on yield and some quality parameters of lamb's lettuce grown in two winter cycles. Sci. Hortic. (Amst.) 187, 80-86 (2015).

166. Tewolde, F. T. et al. Nighttime supplemental LED inter-lighting improves growth and yield of single-truss tomatoes by enhancing photosynthesis in both winter and summer. Front. Plant Sci. 7, 448 (2016).

167. Kumar, K. G. S., Hao, X., Khosla, S., Guo, X. \& Bennett, N. Comparison of HPS lighting and hybrid lighting with top HPS and intra-canopy LED lighting for high-wire mini-cucumber production. Acta Horticulturae 1134, 111-118 (2016).

168. Alcock, C. M. \& Bertling, I. Light-induced colour change in two winter-grown pepper cultivars (Capsicum annuum L.) Acta Horticulturae 956, 275-281 (2012).

169. Xu, H.-l et al. Applications of xerophytophysiology in plant production-LED blue light as a stimulus improved the tomato crop. Sci. Hortic. 148, 190-196 (2012)

170. Massa, G. D., Kim, H.-H., Wheeler, R. M. \& Mitchell, C. A. Plant productivity in response to LED lighting. Hortscience 43,1951-1956 (2008).

171. Hao, X., Guo, X., Chen, X. \& Khosla, S. Inter-lighting in mini-cucumbers: interactions with overhead lighting and plant density. Acta Horticulturae 1107, 291-296 (2015).

172. Zhang, G., Shen, S., Takagaki, M., Kozai, T. \& Yamori, W. Supplemental upward lighting from underneath to obtain higher marketable lettuce (Lactuca sativa) leaf fresh weight by retarding senescence of outer leaves. Front. Plant Sci. 6, 1110 (2015).

173. Horridge, J. S. \& Cockshull, K. E. The effect of the timing of a night-break on flower initiation in Chrysanthemum morifolium Ramat. J. Hortic. Sci. 64 183-188 (1989).

174. Higuchi, Y., Sumitomo, K., Oda, A., Shimizu, H. \& Hisamatsu, T. Day light quality affects the night-break response in the short-day plant chrysanthemum, suggesting differential phytochrome-mediated regulation of flowering. J. Plant. Physiol. 169, 1789-1796 (2012).

175. Thomas, B. \& Vince-Prue, D. Photoperiodism in Plants 143-179 (Academic Press, 1997).

176. Goto, N., Kumagai, T. \& Koornneef, M. Flowering responses to light-breaks in photomorphogenic mutants of Arabidopsis thaliana, a long-day plant. Physiol. Plant 83, 209-215 (1991).

177. Cao, K. et al. Effects of red light night break treatment on growth and flowering of tomato plants. Front. Plant Sci. 7, 527 (2016).

178. Hasperué, J. H., Rodoni, L. M., Guardianelli, L. M., Chaves, A. R. \& Martínez, G. A. Use of LED light for Brussels sprouts postharvest conservation. Sci. Hortic. 213, 281-286 (2016).

179. Takahashi, M., Yoshida, C. \& Komoda, T. Establishing an efficient fruit ripening method for sweet pepper (Capsicum anuum L.) through light irradiation and dark processing. Hortic. J. 87, 73-79 (2018).

180. Liu, J. D. et al. Keeping the rhythm: light/dark cycles during postharvest storage preserve the tissue integrity and nutritional content of leafy plants. BMC Plant Biol. 15, 92 (2015). 